\title{
Peramalan Indeks Harga Saham PT Verena Multi Finance Tbk Dengan Metode Pemodelan ARIMA Dan ARCH-GARCH
}

\author{
Fajriyah Fitriyani ${ }^{(1)}$, Salsabila Fasya A ${ }^{(2)}$, Muhammad Irfan R ${ }^{(3)}$, Teguh Ammar T ${ }^{(4)}$, \\ Universitas Padjadjaran \\ Gedung Departemen Statistika, Jatinangor 45361, Sumedang, Jawa Barat \\ e-mail: muhammad18011@ mail.unpad.ac.id
}

\begin{abstract}
ABSTRAK
Indeks harga saham merupakan indikator penting dalam mencerminkan keseluruhan pergerakan atau naik turunnya harga saham yang ada dalam suatu periode. Indeks harga saham tentunya memiliki fungsi sebagai ukuran trend pasar, dimana menggambarkan keadaan pasar pada saat tertentu. Acuan kinerja suatu pasar modal serta produk hasil investasi dapat diketahui dengan ukuran indeks saham. Oleh karena itu, penelitian ini akan memfokuskan peramalan pada indeks harga saham PT Verena Multi Finance Tbk yang merupakan perusahaan yang bergerak di bidang pembiayaan konsumen. Masih kurangnya keakuratan metode peramalan yang digunakan sebelumnya menjadi latar belakang dari penelitian ini untuk mendapatkan prediksi indeks harga saham PT Verena Multi Finance Tbk dengan metode yang memiliki ketepatan yang tinggi. Data yang dipakai dalam penelitian ini merupakan data sekunder yang didapat dari website yahoofinance.com periode penelitian yaitu Januari 2009 sampai dengan Desember 2019. Metode yang digunakan pada penelitian ini merupakan metode ARIMA, yaitu merupakan metode yang dipakai untuk peramalan data time series. Berdasarkan pengolahan data, didapat model terbaik dengan nilai AIC terkecil yaitu ARIMA $(0,1,1)$. Metode yang selanjutnya digunakan yaitu model ARCH-GARCH yang merupakan metode dalam peramalan data yang memiliki masalah heteroskedastisitas. Berdasarkan hasil analisis yang diperoleh dengan peramalan ARCH-GARCH, didapatkan nilai indeks harga saham pada bulan Desember 2021 adalah sebesar 102.4 dengan MAPE sebesar 22.9971\%. Dengan melakukan penelitian peramalan indeks harga saham ini, diharapkan dapat ditemukan model paling baik yang dapat meramalkan indeks harga saham PT Verena Multi Finance Tbk pada waktu-waktu berikutnya agar dapat menjadi tolak ukur atau sebagai acuan kinerja pasar modal serta produk hasil investasi serta rujukan yang dapat dipercaya untuk melihat kondisi bursa saham pada saat ini.
\end{abstract}

Kata kunci : Indeks harga saham, peramalan, ARIMA, ARCH-GARCH.

\begin{abstract}
The stock price index is an important indicator in reflecting the overall movement of stock prices in a period. This index certainly has a function as an indicator of market trends, which describe market conditions at a certain time. The stock index is very important as a benchmark for the performance of the capital market and investment products. Therefore, this study will focus on forecasting the stock price index of PT Verena Multi Finance Tbk, which is a company engaged in consumer finance. The lack of accuracy of the forecasting method used previously became the background of this study to get a prediction of the monthly period of PT Verena Multi Finance Tbk's stock price index with a method that has higher accuracy. The data used is secondary data obtained from yahoofinance.com for the period January 2009 to December 2019. The method used in this study is the ARIMA model, which is one of the methods used for forecasting time series data. Based on data processing, the best model with the smallest AIC value was obtained, namely ARIMA(0,1,1). The next method used is the ARCH-GARCH model which is a method used in forecasting data that has heteroscedasticity problems without eliminating the heteroscedasticity. Based on the analysis results obtained by the ARCH-GARCH forecasting, the stock price index value in December 2021 was 102.4 with a MAPE of 22,9971\%. By conducting this research, it is hoped that the best model can be found to predict the stock price index of PT Verena Multi Finance Tbk in the following times so that it can be a benchmark for the performance of the capital market and investment products as well as a reliable reference to see the current condition of the stock market.
\end{abstract}

Keywords : Stock price index, Forecasting, ARIMA, ARCH-GARCH.

Fajriyah Fitriyani ${ }^{1}$, Salsabila Fasya $\mathrm{A}^{2}$, Muhammad Irfan $\mathrm{R}^{3}$, Teguh Ammar T ${ }^{4}$

J Statistika Vol. 14, No. 1, (2021) 


\section{PENDAHULUAN}

Pasar modal merupakan suatu tempat dimana dua pihak bertemu, yaitu emiten dan investor yang didalamnya terdapat sebuah kegiatan berhubungan dengan perdagangan dan juga penawaran umum. Keberadaan pasar modal memberikan perusahaan agar dapat memanfaatkan dana yang diperoleh untuk dipakai sebagai bahan pengembangan dalam sebuah penambahan modal, dan kegiatan usaha lainya. Pasar modal juga dapat dijadikan sebagai sarana alternatif bagi masyarakat dalam menginvestasikan harta kekayaanya yang berupa uang dengan harapan yang besar serta mampu memberikan keuntungan dengan risiko yang sekecil mungkin. Peran pasar modal di atas diharapkan dapat memakmurkan masyarakat serta membantu meningkatkan perekonomian suatu negara.

Salah satu investasi yang sering dilakukan di pasar modal adalah saham. Saham adalah suatu surat yang dijadikan sebagai bukti saat seseorang mempunyai atau memegang bagian modal dalam suatu perusahaan. Seseorang dengan kepemilikan saham tentunya mempunyai hak terhadap sebagian aset perusahan. Salah satu cara perusahaan untuk memperoleh modal atau dana untuk mengembangkan bisnis jangka panjang adalah dengan melakukan penerbitan saham, yang dimana saham sendiri dapat diperjualbelikan di bursa saham dengan harga yang berfluktuasi sesuai keadaan perusahaan serta ekonomi.

Indikator yang mencerminkan keseluruhan bergeraknya atau naik turunnya harga saham di suatu periode disebut juga Indeks harga saham. Indeks ini berfungsi sebagai ukuran trend pasar, yang melukiskan keadaan pasar pada saat tertentu. Saat indeks naik, maka saham-saham yang masuk ke dalam indeks pun turut naik dan sebaliknya. Gambar yang ditampilkan dari indeks harga saham dapat dijadikan sebagai suatu pedoman atau acuan para investor untuk menghitung serta menentukan tingkat pengembalian waktu ke waktu. Tingkat pengembalian ini dapat ditentukan dengan membandingkan tingkat indeks saat ini dengan tingkat indeks pada masa lampau.

Penelitian ini mengenai peramalan indeks harga saham memperoleh perhatian yang baik untuk para peneliti pada bidang makroekonomi. Peramalan indeks harga saham dapat dijadikan sebagai tolak ukur atau acuan dalam suatu kinerja pasar modal serta produk hasil investasi, karena dengan adanya indeks ini dapat memberikan kemudahan bagi investor dalam memantau perkembangan pasar saham tanpa harus selalu memerhatikan naik turunnya tiap saham. Penelitian indeks harga saham ini juga dapat dijadikan sebagai suatu rujukan yang dapat dipercaya untuk melihat kondisi bursa saham pada saat ini.

Pada kali ini akan dibahas mengenai indeks harga PT Verena Multi Finance Tbk, yaitu salah satu perusahaan yang bergerak di dalam bidang pembiayaan konsumen periode Januari 2009 Desember 2019.

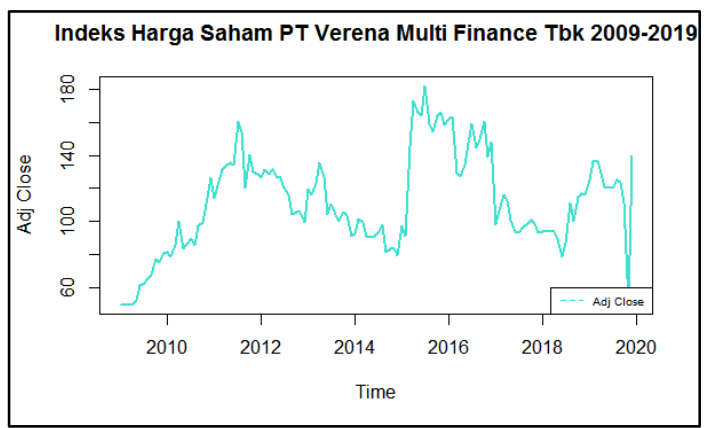

Gambar 1. Plot indeks harga saham PT Verena Multi Finance Tbk Januari 2009 Desember 2019

Terlihat pada Gambar 1. bahwa plot Indeks Harga Saham PT Verena Multi Finance Tbk pada periode Januari 2009 - Desember 2019 menunjukkan data yang tidak stabil atau tingkat variabilitas yang berubah-ubah dari waktu ke waktu. Enders (1995) mengemukakan bahwa data time series dengan ragam tidak konstan disebut sebagai data time series dengan heteroskedastisitas bersyarat (conditional heteroskedastic). Dalam hal ini dibutuhkan suatu metode peramalan yang tepat untuk mengatasi kemungkinan ketidakstabilan data, yaitu tingkat variabilitas yang berubah-ubah dari waktu ke waktu. Metode yang digunakan harus dapat memodelkan sebagian besar data dengan tetap mempertahankan heteroskedastisitas data. Berdasarkan uraian di atas, untuk data yang mengandung heteroskedastisitas seperti pada Indeks Harga Saham PT Verena Multi Finance Tbk, menurut Bollerslev dapat dianalisis menggunakan metode statistik yaitu Generalized Autoregressive Conditional Heteroscedasticity.

\section{METODE PENELITIAN Data Penelitian}

Di penelitian ini data yang akan dipakai merupakan data sekunder yang didapatkan melalui website yahoofinance.com. Data tersebut merupakan data Indeks Harga Saham PT Verena Multi Finance Tbk dengan periode bulanan yang dimulai pada bulan Januari 2009 sampai dengan bulan Desember tahun

Fajriyah Fitriyani ${ }^{1}$, Salsabila Fasya $\mathrm{A}^{2}$, Muhammad Irfan $\mathrm{R}^{3}$, Teguh Ammar $\mathrm{T}^{4}$ /

J Statistika Vol. 14, No. 1, (2021) 
2019. Beberapa metode statistik yang dapat digunakan dalam suatu peramalan data deret waktu dimana peramalan dilakukan dengan memakai data pada masa lalu untuk meramalkan kejadian dimasa berikunya. Penggunaan metode peramalan harus berdasar pada pola datanya. Metode analisis yang digunakan dalam penelitian ini adalah sebagai berikut.

\section{Analisis Runtun Waktu}

Runtun waktu merupakan himpunan observasi data yang terurut dalam waktu (Hanke \& Wichern, 2005). Metode deret waktu merupakan metode yang menganalisis relasi antara variabel yang akan diperkirakan dengan variabel periode atau waktu. Data runtun waktu atau time series merupakan salah satu jenis data yang terdiri dari variabelvariabel yang telah dikumpulkan yang terurut dalam rentang waktu tertentu misalnya mingguan, semesteran dan lain-lain. Pola dalam analisis deret waktu dapat dibagi menjadi empat jenis, yaitu pola data horizontal, trend, musiman, dan siklis (Hanke \& Wichern, 2005).

Untuk dapat mengetahui apakah peristiwa yang diamati mengikuti pola-pola perkembangan yang teratur atau tidak, dapat dilihat dari rangkaian waktunya. Apabila pola yang didapat teratur, artinya dapat dibuat peramalan yang bisa dibilang kuat mengenai tingkah laku gejala dari data yang sedang dianalisis, sehingga dapat membuat rencana-rencana di masa yang berikutnya.

\footnotetext{
ARIMA

ARIMA merupakan model yang dengan penuh mengabaikan variabel independen dalam melakukan suatu peramalan dan suatu model yang berasumsi bahwa data input harus besifat stasioner (Wei W., 1990). ARIMA memakai data masa lampau dan juga masa sekarang dari variabel dependen untuk melakukan peramalan jangka pendek dengan hasil yang akurat dalam sebuah peramalan. Suatu proses $\operatorname{ARIMA}(\mathrm{p}, \mathrm{d}, \mathrm{q})$ didefinisikan dengan persamaan :

$$
D_{p}(B)(1-B)^{d} X_{t}=C_{q}(B) \varepsilon_{t}
$$

Dengan :

$D(B)=1-a_{1} B-a_{2} B^{2}-a_{3} B^{3}-\cdots-a_{p} B^{p}$ (operator AR)

$C(B)=1-b_{1} B-b_{2} B^{2}-b_{3} B^{3}-\cdots-a_{q} B^{q}$ (operator

MA)

dengan

$X_{t} \quad=$ nilai variabel pada waktu ke- $\mathrm{t}$

B = operator backshift

$(1-B)^{d} X_{t}=$ deret waktu stasioner pada pembedaan

ke-d

$\varepsilon_{t} \quad=$ nilai galat pada waktu ke-t
}

Fajriyah Fitriyani ${ }^{1}$, Salsabila Fasya $\mathrm{A}^{2}$, Muhammad Irfan $\mathrm{R}^{3}$, Teguh Ammar T $\mathrm{T}^{4}$

J Statistika Vol. 14, No. 1, (2021)

$p \quad=$ order $\mathrm{AR}$

$d \quad=$ order differencing

$q \quad=$ order MA

Tahap pertama yang dilakukan yaitu uji asumsi meliputi uji stasioneritas dalam rata-rata dan uji stasioneritas dalam varians. Selanjutnya, indentifikasi model dan penaksiran parameter. Kemudian pemilihan model ARIMA terbaik. Setelah didapatkan model ARIMA terbaik, akan dilakukan pengujian efek heteroskedastisitas terhadap model, pendugaan parameter dan pemilihan model ARCH-GARCH terbaik. Selanjutnya model yang didapatkan akan digunakan untuk memprediksi indeks saham.

\section{Stasioneritas Data}

Menurut Makridakis (1999) agar dapat dilakukan analisis yaitu memakai metode ARIMA, suatu data time series wajib berasumsi stasioneritas. Asumsi ini digunakan untuk memperkecil kekeliruan dari model yang dibentuk. Ada 2 jenis bentuk kestasioneran data, yaitu stasioneritas dalam mean atau rata-rata dan juga stasioneritas dalam varians. Hal pertama yang harus dilakukan yaitu melakukan plot data indeks saham dari periode penelitian yaitu bulan tahun 2009 sampai bulan Desember 2019.

Dari plot data, dapat dilihat secara visual dan diidentifikasi apakah data bersifat stasioneritas atau tidak. Suatu proses tidak stasioner dalam rata-rata apabila terdapat tren (menurun atau naik) dalam data. Sedangkan ketidakstasioneran dapat dilihat apabila terdapat heteroskedastisitas dalam pergerakan data. Data runtun waktu dapat disebut telah stasioner jika mean data fluktuasi pada sekitar nilai ratarata yang tetap dari waktu ke waktu, sedangkan data runtun waktu dapat disebut telah stasioner dalam varian apabila data fluktuasi dengan ragam yang tetap dari waktu ke waktu (Juanda, Bambang, \& Junaidi, 2012).

Namun, stasioneritas berdasarkan plot data akan menghasilkan penilaian yang subjektif. Stasioneritas data indeks saham juga dapat dilaksanakan dengan uji unit root menggunakan metode yaitu Augmented Dickey-Fuller Test. Berikut model yang dapat dipakai untuk Uji ADF :

$\Delta Y_{t}=\delta Y_{t-1}+u_{t} \quad$ (tanpa intercept)

$\Delta Y_{t}=\beta+\delta Y_{t-1}+u_{t} \quad$ (dengan intercept)

$\Delta Y_{t}=\beta_{1}+\beta_{2 t}+\delta Y_{t-1}+u_{t} \quad$ (intercept trend waktu)

- Hipotesis penelitian

$H_{0}: \delta=0$ (terdapat unit root, data tidak memenuhi asumsi stasioner)

$H_{1}: \delta \neq 0$ (tidak terdapat unit root, data stasioner atau memenuhi asumsi)

- $\quad$ Statistik Uji 


$$
\hat{\tau}=\frac{\hat{\delta}}{\operatorname{SE} \hat{\delta}}
$$

\section{- Kriteria Uji}

Tolak $H_{0}$ jika $p$-value $<\alpha$, artinya data telah stasioner, terima $H_{0}$ dalam hal lainnya.

2. Melakukan Identifikasi Model

Langkah selanjutnta melakukan identifikasi model yang dilakukan pada data yang telah bersifat stasioner. Jika data yang dipakai masih belum memenuhi syarat stasioneritas, maka data tersebut harus dilakukan differencing apabila data tidak stasioner dalam rata-rata atau mean dan dilakukan transformasi apabila belum stasioner dalam varians. Selanjutnya, setelah data yang digunakan bersifat stasioner, dapat ditentukan model yang berbentuk ARMA atau kepanjangan dari Autoregressive Moving Average yang akurat dalam pengambaran sifat data, hal ini dilakukan dengan melakukan perbandingan plot pada sampel ACF/PACF dengan sifat fungsi ACF/PACF yang teoritis. Dalam sebuah proses penentuan model yang akurat tentunya dilaksanakan dengan mengidentifikasi orde AR dan MA pada plot ACF dan juga plot PACF. Dalam menentukan orde pada model ARIMA (p,d,q), orde $\mathrm{p}$ dan $\mathrm{q}$ dapat dilihat dari plot ACF/PACF dan untuk orde d didapatkan dari banyaknya proses differencing yang dilakukan untuk memperoleh data yang telah stasioner dalam rata-rata. Plot ACF berguna untuk mengidentifikasi orde MA dan plot PACF berguna untuk mengidentifikasi orde AR.

Identifikasi orde AR dan juga MA dapat dilaksanakan sesuai dengan correlogram yang diperoleh. Jika ACF turun secara eksponensial dan PACF signifikan pada lag $\mathrm{p}$ maka model yang diperoleh adalah $\mathrm{AR}(\mathrm{p})$, sebaliknya jika PACF turun secara eksponensial dan ACF signifikan pada lag q maka model yang diperoleh adalah MA(q). Jika ACF turun dengan eksponensial setelah lag q dan PACF turun dengan eksponensial setelah lag $p$ maka bentuk model yang diperoleh adalah $\operatorname{ARMA}(\mathrm{p}, \mathrm{q})$.

3. Penaksiran Parameter

Apabila telah menentukan bentuk model yang sekiranya sudah sesuai untuk data, maka berikutnya akan dicari nilai penaksir terhadap parameter yang ada di dalam model, contohnya koefisien model ARMA dan nilai variansi residual. Untuk mencari penaksir model ARMA dapat diketahui menggunakan metode Maksimum Likelihood Estimator (MLE), Least Square, Hannan Rissanen, dan lainnya. Selanjutnya, untuk menguji apakah koefisien hasil taksiran signifikan atau tidak, gunakanlah pengujian dengan menggunakan statistik uji $\mathrm{t}$ yang berdistribusi student-t dengan derajat bebas $\mathrm{n}-1, \mathrm{n}=$ banyaknya sampel. Apabila ada koefisien yang tidak signifikan, maka koefisien tersebut dapat dibuang dari model dan setelah itu estimasi kembali model dengan tidak melibatkan order yang tidak signifikan. Apabila $\theta$ merupakan parameter model ARIMA dan $\theta$ merupakan nilai estimasi atau taksiran parameter tersebut, dan $S(\theta)$ merupakan standar error nilai estimasi atau taksiran $\theta$, uji signifikansi parameter dapat dilaksanakan seperti langkah berikut.

- Hipotesis penelitian

$H_{0}: \theta=0$ (artinya parameter model ARIMA BoxJenkins tidak signifikan)

$H_{1}: \theta \neq 0$ (artinya parameter model ARIMA BoxJenkin signifikan)

- Statistik uji

$$
\hat{\tau}=\frac{\hat{\delta}}{\operatorname{SE} \hat{\delta}}
$$

\section{- Kriteria uji}

Tolak $H_{0}$ apabila $\mid$ thitung $\mid \geq \operatorname{ttabel}(\alpha, n-p)$ dengan p merupakan banyak parameter, terima $H_{0}$ dalam hal lainnya.

\section{Pemeriksaan Asumsi}

Apabila sudah menaksir nilai-nilai parameter dari model ARIMA, langkah yang harus dilakukan berikutnya adalah diagnostic check model yang sudah kita estimasi sebelumnya dengan cara memverifikasi model sesuai sifat pada data. Apabila model sudah tepat, maka data yang dihitung dengan model, pastinya akan memiliki sifat yang tidak beda jauh daripada data aslinya. Residual yang telah dihitung didapatkan dari model yang sudah diestimasi yang memenuhi asumsi dari eror dari model teoritis, seperti normalitas residual, White Noise, dan lain sebagainya. Untuk mengetahui residual berautokorelasi atau tidak, hal tersebut dapat diketahui dengan cara melakukan uji korelasi serial, yaitu menggunakan uji Q-Ljung Box (Box \& Pierce, 1970).

A. Uji Q-Ljung Box

- Hipotesis penelitian

$H_{0}: \rho_{1}=\rho_{2}=\rho_{3}=\cdots=\rho_{k}=0$ (artinya residual tidak berautokorelasi)

$H_{1}$ : paling tidak ada satu $\rho_{k} \neq 0$ (artinya residual berautokorelasi)

- Statistik uji

$$
Q=n^{\prime}\left(n^{\prime}+2\right) \sum_{k=1}^{m} \frac{r k^{2}}{n^{\prime}}
$$

Fajriyah Fitriyani ${ }^{1}$, Salsabila Fasya $\mathrm{A}^{2}$, Muhammad Irfan $\mathrm{R}^{3}$, Teguh Ammar $\mathrm{T}^{4}$ /

J Statistika Vol. 14, No. 1, (2021) 
Mengikuti distribusi Chi-Kuadrat dengan $d b=(k-p-q-P-Q)$, dan $n^{\prime}=n-(d+$ $S D)$.

$d$ : orde pembedaan (differencing) bukan faktor seasonal

$D$ : orde pembedaan (differencing) faktor seasonal

$S$ : lag periode maksimum

$r k$ : autokorelasi time lag 1,2, $3 \ldots, k$.

- Kriteria uji

Tolak $H_{0}$ apabila $Q>\chi^{2}(\alpha, d b)$ atau $p-$ value $<\alpha$, terima $H_{0}$ dalam hal lainnya.

B. Uji Kolmogorov-Smirnov

- Hipotesis penelitian

$H_{0} \quad: \quad F\left(\alpha_{t}\right)=F_{0}\left(\alpha_{t}\right) \quad$ (Residualnya berdistribusi normal)

$H_{1}: F\left(\alpha_{t}\right) \neq F_{0}\left(\alpha_{t}\right) \quad$ (Residualnya tidak distribusi normal)

- $\quad$ Statistik uji

$$
D=\operatorname{maks}\left|F_{0}(x)=S_{N}(x)\right|
$$

dengan :

$D \quad$ : difference absolute

$F_{0}(x)$ : fungsi distribusi kumulatif teoritis dibawah Hipotesis nol

$S_{N}(x)$ : distribusi frekuensi kumulatif yang diobservasi dari suatu sampel random

- Kriteria uji

Tolak $H_{0}$ jika nilai $D>$ nilai $D^{*}(\alpha)$, terima dalam hal lainnya. $D^{*}(\alpha)$ disini merupakan nilai kritis yang didapatkan dari kolmogorovsmirnov tabel.

5. Pemilihan Model ARIMA terbaik

Apabila terdapat 2 metode peramalan yang digunakan pada suatu data, pilihlah model terbaik berdasarkan pada error peramalan (Juanda, Bambang, \& Junaidi, 2012). Pemilihan model terbaik adalah metode yang memberikan kesalahan peramalan terkecil. Untuk memilih model terbaik, pilihlah model yang mengecilkan nilai kriteria Akaike Information Criteria (AIC), yang akan digunakan pada penelitian ini. Berikut persamaannya.

$$
\begin{gathered}
A I C: A I C=n \ln \left(\sigma \varepsilon^{2}\right)+2(m) \\
\sigma \varepsilon^{2}=\frac{S S E}{n}
\end{gathered}
$$

Dengan,

n : banyaknya pengamatan

m : banyaknya parameter dalam model

SSE : merupakan singkatan dari Sum of Squared Error. SSE bisa ditaksir dari jumlah kuadrat seluruh residual. Semakin kecil nilai Akaike Information Criteria (AIC) maka semakin baik model yang didapatkan.

\section{ARCH}

Model ARCH atau kepanjangan dari Autoregressive conditional Heteroscedasticity merupakan hasil pengembangan Engle. Rata-rata serta varian suatu data dengan deret waktu yang dimodelkan simultan dengan varian residual yang berbeda-beda karena adanya perubahan ragam residual yang tergantung dari seberapa besar residual di masa lampau.

Pada model $\mathrm{ARCH}(\mathrm{m})$, diperoleh variansi dari $r_{t}$ kondisional terhadap informasi masa lalu sebagai.

$\operatorname{Var}\left(r_{t} \mid \zeta_{t-1}\right)=E\left(\varepsilon t^{2} \mid F_{t-1}\right)=\sigma t^{2}$

dapat digambarkan dengan persamaan:

$$
\sigma_{t}^{2}=\alpha_{0}+\sum_{i=1}^{m} a_{i} \varepsilon_{t-1}^{2}
$$

dengan $\alpha_{0}>0, \alpha i \geq 0, i=1,2, \ldots, m$. Kondisi $\alpha i \geq$ 0 diperlukan agar persamaan vitalitas tidak negatif. Jika semua $\alpha i=0$, maka variansi bersyarat $\sigma^{2}$ akan menjadi konstanta $\alpha_{0}$ dan $\varepsilon_{t}$ akan merupakan proses IID yang bersifat homoskedastik.

Pada model ARCH, proses $\varepsilon_{t}$ menunjukkan komponen random dari model (sering disebut sebagai proses White Noise), dimana $\left(\varepsilon_{t}\right)=0$ dan bersifat tidak berkorelasi dengan waktu lampau atau waktu yang akan datang, yakni sebagai berikut.

$$
E\left(\varepsilon_{\varepsilon_{t} \varepsilon_{s}}\right)= \begin{cases}0, & t \neq s \\ \sigma_{t}^{2}, & t=s\end{cases}
$$

Dari persamaan di atas walaupun proses $\varepsilon t$ sifatnya tidak saling berkorelasi namun proses tersebut tidak bersifat independen. Dalam model $\mathrm{ARCH}(\mathrm{m})$, proses $\varepsilon t$ dibangkitkan oleh proses:

$\varepsilon_{t}=\sigma_{t} v_{t}$

dimana $\boldsymbol{\sigma}_{\boldsymbol{t}}$ adalah akar positif dari $\boldsymbol{\sigma}_{\mathbf{2}}$ dan $\boldsymbol{v}_{\boldsymbol{t}}$ adalah suatu proses IID (independent dan identically distributed), $v_{t}$ merupakan white noise dimana ratarata atau mean-nya sama dengan nol dan variansi satu, dan $v_{t}$ sering diasumsikan normal standar $\mathrm{N}(0,1)$ atau berdistribusi student-t, dan lebih lanjut, $v_{t}$ independen dengan $\varepsilon_{t}, s<t$. Asumsi ini mengakibatkan distribusi bersyarat dari $\varepsilon t$ akan berdistribusi normal dengan mean 0 dan variansi $\sigma_{2}$ (Wei W. ,1990). Model ARCH(p) bisa ditulis dalam bentuk sebagai berikut:

$$
\sigma_{\mathrm{t}}^{2}=\alpha_{0}+\alpha_{1} \varepsilon^{2}{ }_{t-1}+\alpha_{2} \varepsilon^{2}{ }_{t-2}+\cdots+\alpha_{p} \varepsilon^{2}{ }_{t-p}
$$

\section{GARCH}

Model GARCH merupakan model hasil pengembangan Bollerslev yang muncul tahun 1986. Model ini adalah model kelanjutan dari

Fajriyah Fitriyani ${ }^{1}$, Salsabila Fasya $A^{2}$, Muhammad Irfan $R^{3}$, Teguh Ammar $T^{4}$ /

J Statistika Vol. 14, No. 1, (2021) 
ARCH. Tujuan model GARCH dibangun pada model ARCH adalah untuk menghindari adanya ordo yang tingginya berlebihan. Sesuai dengan prinsip parsimony yaitu dengan memilih model yang lebih sederhana, maka variansinya akan selalu positif. (Model GARCH $(p, q)$ dapat dinyatakan dalam bentuk persamaan berikut :

$$
\begin{gathered}
\sigma^{2}{ }_{t}=\alpha_{0}+\alpha_{1} \varepsilon^{2}{ }_{t-1}+\cdots+\alpha_{p} \varepsilon^{2}{ }_{t-p}+\lambda_{1} \sigma^{2}{ }_{t-1}+ \\
\ldots+\lambda_{q} \sigma^{2}{ }_{t-q}
\end{gathered}
$$

Dimana,

$$
\begin{array}{ll}
\sigma_{t}{ }^{2} & =\text { kondisional varians } \\
\alpha_{0}, \alpha_{1} & =\text { konstanta } \\
\varepsilon^{2}{ }_{t-p} & =\text { residual bulan } \mathrm{t}-\mathrm{p} \\
\sigma^{2} t-q & =\text { varians kondisional bulan } \mathrm{t}-\mathrm{q} \\
\alpha_{p} & =\text { parameter ARCH, untuk } \mathrm{p}=1,2,3, \ldots, \mathrm{p} \\
\lambda_{q} & =\text { parameter GARCH, untuk } \mathrm{q}=1,2,3, \ldots, \mathrm{q}
\end{array}
$$

Tidak semua data runtun waktu mengandung efek heteroskedastisitas, diperlukan pengujian agar dapat mengetahui apakah ada tidaknya efek heteroskedastisitas dalam data runtun waktu.

Pengujian dapat dilakukan dengan cara memeriksa fungsi autokorelasi dari $\varepsilon^{2}$ (Wei W., 2006). Langkah-langkah yang dapat ditempuh adalah:

1. Estimasi model untuk mean dari proses $\left\{r_{t}\right\}$, misal menggunakan model ARMA atau model regresi. Selanjutnya, hitung nilai fitted residual dari model ini $\varepsilon_{t}=r_{t}-\hat{\mu_{t}}$ dan $\hat{\varepsilon}_{\mathrm{t}}^{2}$ dan selanjutnya hitunglah variansi dari $\hat{\varepsilon}_{\mathrm{t}}^{2}$ sebagai berikut:

$$
\sigma^{2}=\frac{\sum_{t=1}^{n} \varepsilon_{t}^{2}}{n}
$$

dimana $\mathrm{n}$ menyatakan banyaknya data dari residual.

2. Hitung dan buatlah plot sampel ACF dan PACF dari $\hat{\varepsilon_{\mathrm{t}}^{2}}$. Fungsi sampel ACF dari $\hat{\varepsilon_{\mathrm{t}}^{2}}$ dapat dihitung sebagai berikut:

$$
\rho_{k}=\frac{\sum_{t=k+1}^{T}\left(\varepsilon_{t}^{2}-\sigma^{2}\right)\left(\varepsilon_{t-k}^{2}-\sigma^{2}\right)}{\sum_{t=1}^{T}\left(\varepsilon_{t}^{2}-\sigma^{2}\right)^{2}}
$$

Dan sampel PACF dihitung dengan menggunakan bentuk sampel PACF untuk proses autoregresi bagi $\hat{\varepsilon_{t}^{2}}$. Untuk sampel yang berukurun besar, sampel ACF dan PACF untuk $\hat{\varepsilon_{\mathrm{t}}^{2}}$ dibandingkan dengan $\pm \frac{2}{\sqrt{n}}$. Apabila terdapat nilai sampel ACF dan PACF yang signifikan berbeda dengan nol (yakni nilainya berada di luar interval $\pm \frac{2}{\sqrt{n}}$ maka efek heteroskedastisitas dikatakan signifikan.

\section{ARCH-GARCH}

Atas dasar tersebut terdapat langkah-langkah untuk menentukan model ARCH-GARCH. Maka tahapan pemodelan metode ARCH-GARCH pada data indeks harga saham PT Verena Multi Finance Tbk dari periode penelitian bulan Januari 2009 sampai dengan bulan Desember 2019, terdiri atas beberapa tahapan sebagai berikut.

1. Pengujian Efek Heteroskedastisitas

Apabila model ARIMA telah didapatkan, maka dapat dilakukan pengujian untuk mengetahui keberadaan efek heteroskedastisitas. Untuk menguji efek heteroskedastisitas pada data dilakukan pengujian pada residual kuadrat dari model terbaik yang telah diperoleh sebelumnya, yaitu dengan memakai uji Q-Ljung Box (Box \& Pierce, 1970). Hipotesis sebagai berikut:

- Hipotesis penelitian

$$
H_{0}:(1)=\rho(2)=\cdots=\rho(k)=0
$$

(artinya tidak terdapat efek heteroskedastisitas) $H_{1}$ : paling tidak terdapat satu $k \in 1,2, \ldots, m$ dengan $\rho(k) \neq 0$

(artinya terdapat efek heteroskedastisitas)

- $\quad$ Statistik uji

$$
Q=(n+2) \sum_{i-1}^{m} \frac{p_{i}}{n-i}
$$

dengan $\mathrm{i}=$ banyak lag

- Kriteria uji

Tolak $H_{0}$ apabila $Q>\chi(\mathrm{i})^{2}$ atau $\mathrm{p}$-value $<\alpha$ yang berarti dalam residual kuadrat terdapat ARCH/GARCH, dan terima $H_{0}$ dalam hal lainnya.

2. Penaksiran Parameter GARCH

Setelah melakukan pengujian keberadaan efek heteroskedastisitas, lihat plot ACF dan PACF dari residual kuadrat untuk pembentukan model ARCHGARCH. Langkah selanjutnya adalah dari beberapa model yang telah didapatkan akan dilakukan penaksiran parameter model menggunakan maximum likelihood. Penaksiran parameter ini dilaksanakan untuk menguji keberartian parameter dalam model.

3. Pemilihan Model GARCH Terbaik

Setelah melakukan penaksiran parameter pada model GARCH, maka kita bisa tentukan model terbaiknya. Pilihlah model yang mengecilkan nilai kriteria seperti Akaike Information Criteria (AIC). (Nachrowi D., 2006)

4. Akurasi Peramalan

Model peramalan yang didapatkan akan divalidasi agar dapat mengetahui akurasi metode peramalan dalam pemodelan data time seriesnya. Salah satunya adalah dengan menghitung rata-rata penyimpangan absolut atau MAD. MAD menunjukan adanya error pada data. Hal ini dapat diperoleh dengan mencari rata-rata nilai absolut error dari semua hasil forecasing. Nilai absolut

Fajriyah Fitriyani ${ }^{1}$, Salsabila Fasya $A^{2}$, Muhammad Irfan $\mathrm{R}^{3}$, Teguh Ammar $\mathrm{T}^{4}$ /

J Statistika Vol. 14, No. 1, (2021) 
disini digunakan untuk menghindari nilai error yang positif serta nilai error yang negatif saling meniadakan. Persamaannya dapat ditulis seperti di bawah ini.

$$
M A D=\frac{1}{n} \sum_{t=1}^{m}|X t-F t|
$$

Dengan,

$X$ : data aktual observasi

$F$ : data peramalan.

\section{HASIL DAN PEMBAHASAN ARIMA}

Dengan menggunakan software R, akan dilakukan analisis dengan tahapan sebagai berikut.

\section{Stasioneritas Data}

Hal paling awal yang seharusnya dilakukan dalam mengecek kestasioneritasan data yaitu dengan membuat plot data deret waktu pada data indeks harga PT Verena Multi Finance Tbk dari periode Januari 2009 sampai Desember 2019. Pada plot data akan dilihat kestasioneritasan data dalam rerata dan varians.

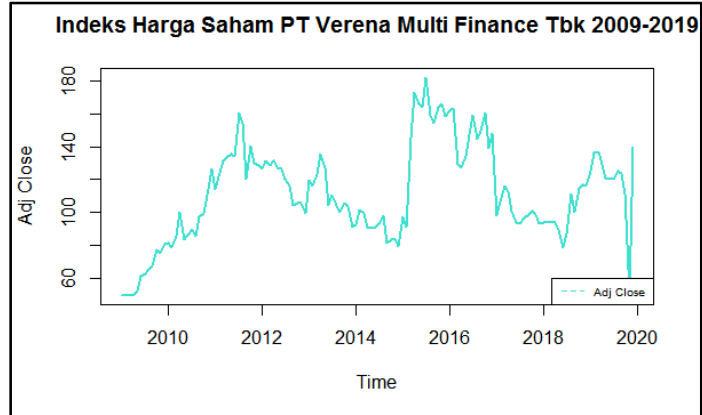

Gambar 1. Plot indeks harga saham PT Verena Multi Finance Tbk Januari 2009 Desember 2019

Berdasarkan Gambar 1. terlihat bahwa data indeks harga saham PT Verena Multi Finance Tbk secara visual menunjukkan adanya pola trend pada selang waktu tertentu, seperti pada tahun 2009 hingga 2011 terlihat pola trend naik. Namun, setelah tahun 2011 hingga tahun 2015 terlihat pola trend menurun. Secara keseluruhan, plot data pada Gambar 1. tidak memiliki pola musiman dan pola stasioner karena data tidak menyebar di sekitaran rerata.

Kestasioneritasan dalam varians pada data dapat diperiksa menggunakan uji Box-Cox. Nilai lambda yang didapatkan setelah dilakukan uji Box-Cox terhadap data indeks harga saham PT Verena Multi
Finance Tbk adalah sebesar 0.1362227. dalam hal ini, data tidak memiliki sifat kestasioneritasan dalam varians, maka mesti ditransformasi. Sesudah dua kali ditransformasi, ternyata data memiliki nilai lambda yang meningkat hingga sebesar 0.7926443. Artinya, data sudah memenuhi salah satu syarat, yaitu stasioner dalam varians.

Pemeriksaan kestasioneritasan dalam rerata pada data dapat memakai Uji Unit Root dengan metode Augmented Dicky-Fuller (ADF) dengan hipotesis nolnya adalah data indeks harga saham PT Verena Multi Finance Tbk belum stasioner. Sedangkan untuk hipotesis alternatifnya adalah data indeks harga saham sudah stasioner. Berdasarkan pengujian ADF pada data indeks harga saham PT Verena Multi Finance Tbk diperoleh $p$-value = 0.1788. Maka, $\mathrm{H}_{0}$ diterima artinya data indeks harga saham tidak stasioner. Oleh karena itu perlu dilakukan pembedaan (differencing). Sesudah data dilakukan differencing satu kali, didapatkan $p$ value sebesar 0.01, artinya $\alpha=0.05$ lebih besar dari $p$-value. Sehingga, dapat disimpulkan bahwa data sudah memiliki kestasioneran dalam rerata.

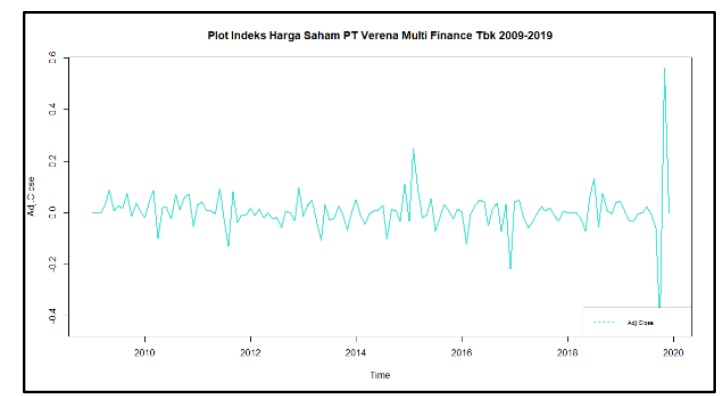

Gambar 2. Plot Indeks Harga Saham PT Verena Multi Finance Tbk Januari 2009 Desember 2019 yang Sudah Stasioner

Pada gambar tersebut data dilihat bahwa plot data deret waktu indeks harga saham PT Verena Multi Finance Tbk sudah memiliki kestasioneran baik dalam varians maupun dalam rerata dengan differencing sebanyak sekali.

\section{Identifikasi Model}

Sesudah diuji asumsi kestasioneritasannya baik dalam varians maupun rata-rata terpenuhi, lalu tahapan berikutnya adalah penentuan orde model ARIMA yaitu $\operatorname{AR}(p)$ dan $\operatorname{MA}(q)$ yang didapatkan melalui penggambaran pola ACF dan PACF menurut data awal yang telah diuji kestasioneritasan pada varians dan rerata, sehingga dari plot ACF dan PACF bisa mengidentifikasi model ARIMA yang dibentuk.

Fajriyah Fitriyani ${ }^{1}$, Salsabila Fasya $\mathrm{A}^{2}$, Muhammad Irfan $\mathrm{R}^{3}$, Teguh Ammar T ${ }^{4}$

J Statistika Vol. 14, No. 1, (2021) 


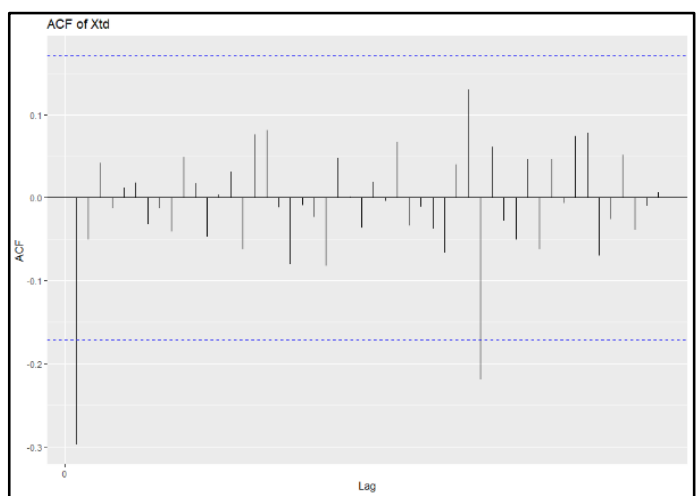

Gambar 3. Plot ACF Data Indeks Harga Saham PT Verena Multi Finance Tbk Januari 2009 - Desember 2019

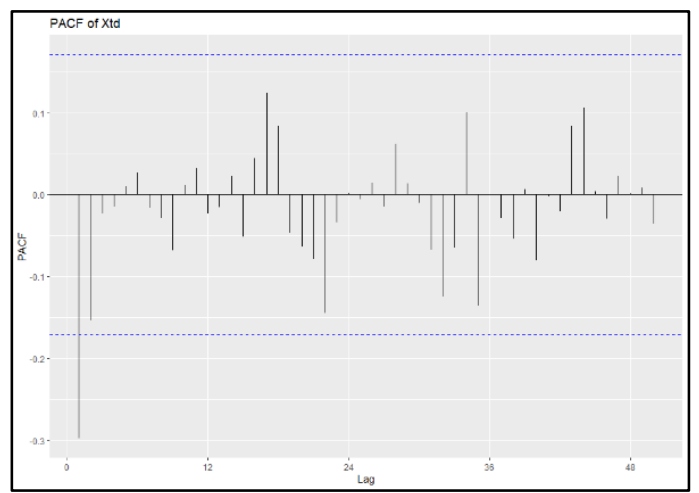

Gambar 4. Plot PACF Data Indeks Harga Saham PT Verena Multi Finance Tbk Januari 2009 - Desember 2019
Berdasarkan Gambar 3. dapat dilihat bahwa pola yang terbentuk dapat diduga beberapa nilai yaitu pada plot ACF dapat diidentifikasi orde MA melihat pada lag yang signifikan, sehingga diperoleh MA(0) dan MA(1). Berdasarkan Gambar 4. dapat dilihat pola PACF yang signifikan karena cut off after lag 1 sehingga plot dapat diidentifikasi orde AR yaitu AR(0) dan AR(1). Selain itu, sorde untuk differencing adalah $\mathrm{d}=1$ karena data dilakukan differencing sekali. Beberapa alternatif model yang dapat digunakan adalah :

1. Model 1 : model ARIMA $(1,1,0)$

2. Model $2:$ model ARIMA $(0,1,1)$

3. Model 3 : model ARIMA $(1,1,1)$

Sesudah didapatkan model dugaan ARIMA maka langkah berikutnya yaitu menaksir parameter untuk setiap model. Hasil penaksiran parameter tersebut akan diuji signifikansinya untuk melihat apakah parameter yang ditaksir memiliki keberartian atau pantas termasuk ke dalam suatu model. Untuk pengujian signifikansi parameter, memakai statistik uji t-test melalui kriteria signifikan apabila $\alpha$ lebih besar dari $p$-value.

- Hipotesis nolnya adalah parameter yang ditaksir tidak signifikan, sedangkan untuk hipotesis alternatifnya adalah parameter yang ditaksir sudah signifikan.

- $\quad$ Taraf Signifikan : $\alpha=5 \%=0.05$

- $\quad$ Statistik Uji : Uji t-test

$$
t_{\text {hitung }}=\frac{\theta}{\operatorname{se}(\hat{\theta})}
$$

\section{Penaksiran dan Uji Signifikansi Parameter}

Tabel 1. Hasil penaksiran parameter beserta uji signifikansi parameter

\begin{tabular}{|c|c|c|c|c|c|c|}
\hline Model & Parameter & Estimasi & $\begin{array}{c}\text { Standar } \\
\text { Error }\end{array}$ & t-hitung & $p$-value & Keterangan \\
\hline ARIMA(1,1,0) & AR(1) & -0.301009 & 0.098073 & -3.0683 & 0.002146 & Signifikan \\
\hline ARIMA(0,1,1) & MA(1) & -0.311967 & 0.084173 & -3.7063 & 0.0002103 & Signifikan \\
\hline ARIMA(1,1,1) & AR(1) & -0.02168 & 0.28078 & -0.0772 & 0.9385 & $\begin{array}{c}\text { Tidak } \\
\text { Signifikan }\end{array}$ \\
\cline { 2 - 7 } & MA(1) & -0.29392 & 0.24935 & -1.1787 & 0.2385 & $\begin{array}{c}\text { Tidak } \\
\text { Signifikan }\end{array}$ \\
\hline
\end{tabular}

\section{Pemeriksaan Asumsi}

Model yang terpenuhinya asumsi residual bersifat white noise atau residual yang tidak berautokorelasi adalah salah satu ciri model ARIMA yang baik. Agar mengetahui residual berautokorelasi atau tidak dilakukan pengujian dengan uji $Q$-Ljung Box. Apabila nilai alpha 0.05 lebih kecil dari p-value maka residual memenuhi syarat tidak berautokorelasi. Hasil pengujian memakai uji $Q$ Ljung Box terlihat bahwa model $\operatorname{ARIMA}(1,1,0)$ beserta $\operatorname{ARIMA}(0,1,1)$ terpenuhi asumsi residual tidak berautokorelasi dengan nilai $p$-value berturutturut untuk setiap model adalah 0.6955 dan 0.9517 . Selanjutnya akan dilakukan pengujian kenormalitasan residual memakai uji KolmogorovSmirnov. Apabila nilai alpha 0.05 lebih kecil dari p-value maka asumsi normalitas residual terpenuhi.

Fajriyah Fitriyani ${ }^{1}$, Salsabila Fasya $\mathrm{A}^{2}$, Muhammad Irfan $\mathrm{R}^{3}$, Teguh Ammar T ${ }^{4}$

J Statistika Vol. 14, No. 1, (2021) 
Hasil pengujian memakai uji Kolmogorov-Smirnov memperlihatkan jika pada model $\operatorname{ARIMA}(1,1,0)$ beserta model ARIMA $(0,1,1)$ memenuhi dugaan kenormalitasan residual dengan nilai $p$-value berturut-turut untuk setiap model adalah 0.05112 dan 0.07081 .

\section{Pemilihan Model ARIMA Terbaik}

Berdasarkan dua model dugaan ARIMA yang dibentuk sebelumnya, semua parameter model signifikan, dan begitu pula untuk asumsi white noise dan normalitas residual, maka asumsi tersebut terpenuhi oleh kedua model tersebut. Untuk memilih model dugaan ARIMA terbaik, dapat dilihat dari model yang memiliki nilai AIC terkecil dari kedua model ARIMA tersebut. Berikut ini adalah nilai AIC untuk setiap dugaan model.

Tabel 2. Nilai AIC masing-masing model ARIMA indeks harga saham PT Verena Multi Finance Tbk

\begin{tabular}{|c|c|c|}
\hline No & Model ARIMA & Nilai AIC \\
\hline 1 & ARIMA $(1,1,0)$ & 1079.001 \\
\hline 2 & ARIMA $(0,1,1)$ & 1077.736 \\
\hline
\end{tabular}

Jika dilihat dari tabel diatas, model yang mempunyai nilai AIC terkecil ialah model ARIMA(0,1,1). Maka, dapat diambil kesimpulan bahwa model ARIMA yang terpilih adalah model $\operatorname{ARIMA}(0,1,1)$. Untuk mendapatkan persamaan dari model ARIMA(0,1,1), substitusikan nilai estimasi parameter pada Tabel 1. ke dalam persamaan berikut.

$$
X_{t}=\mu^{\prime}+\phi X_{t-1}+\varepsilon_{t}
$$

Sehingga akan diperoleh persamaan sebagai berikut.

$$
X_{t}=-0.3120 X_{t-1}+\varepsilon_{t}
$$

\section{ARCH-GARCH}

\section{Pengujian Efek Heteroskedastisitas}

Sesudah diperoleh model ARIMA terbaik, tahap berikutnya yaitu pengujian efek heteroskedastisitas terhadap residual kuadrat model terbaik ialah model ARIMA(0,1,1). Pengujian efek heteroskedastisitas dilakukan dengan menggunakan uji Q-Ljung Box. Apabila alpha 0.05 lebih besar dari $p$-value artinya ada efek heteroskedastisitas. Pada hasil uji $Q$-Ljung Box diperoleh hasil nilai $p$ value yang lebih kecil dari alpha 0.05 yaitu sebesar 4.031e-06. Maka, dapat diambil kesimpulan bahwa ada efek heteroskedastisitas pada model $\operatorname{ARIMA}(0,1,1)$.

\section{Pengujian Efek ARCH pada Model ARIMA}

Pengujian efek ARCH dalam residual persamaan kuadrat terkecil tunggal dapat memakai uji Langrange Multiplier (LM) dengan dugaan yaitu :

Hipotesis nol berasumsi bahwa tidak ada efek ARCH pada model ARIMA, sedangkan hipotesis alternatif berkata sebaliknya, yaitu ada efek ARCH pada model ARIMA.

Apabila nilai alpha 0.05 lebih besar dari p-value maka residual memiliki efek ARCH pada model ARIMA(0,1,1). Hasil pengujian menggunakan uji Langrange Multiplier (LM) nampak bahwa pada model ARIMA $(0,1,1)$ terdapat efek ARCH karena hasil perhitungan nilai $p$-value sebesar kurang dari 2.2e-16. Maka, setelah itu dilanjutkan dengan tahap mengidentifikasi model ARCH-GARCH.

\section{Identifikasi Model ARCH-GARCH}

Pada tahap ini mengidentifikasi model $\operatorname{ARCH}(p)$ dan $\operatorname{GARCH}(p, q)$ mengikuti plot ACF beserta plot PACF residual kuadrat model $\operatorname{ARIMA}(0,1,1)$. Adapun plot ACF beserta plot PACF residual kuadrat model $\operatorname{ARIMA}(0,1,1)$ adalah sebagai berikut.

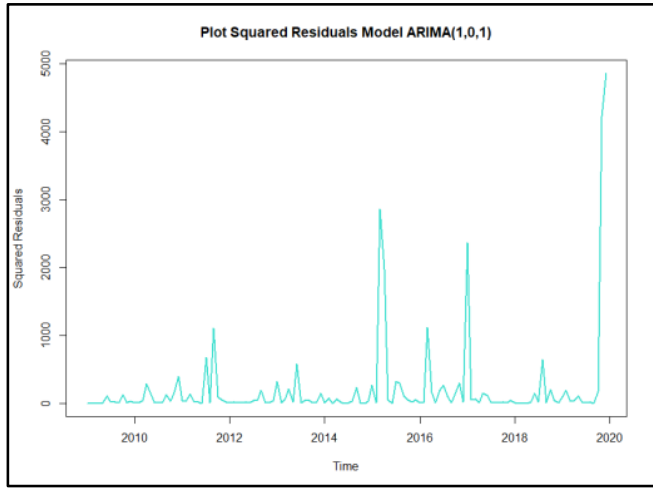

Gambar 5. Plot Residual Kuadrat Model $\operatorname{ARIMA}(0,1,1)$

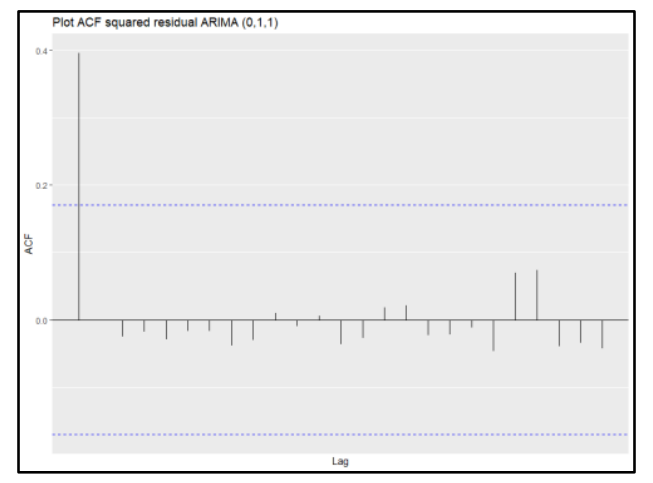

Gambar 6. Plot ACF Residual Kuadrat Model $\operatorname{ARIMA}(0,1,1)$

Fajriyah Fitriyani ${ }^{1}$, Salsabila Fasya $\mathrm{A}^{2}$, Muhammad Irfan $\mathrm{R}^{3}$, Teguh Ammar T ${ }^{4}$

J Statistika Vol. 14, No. 1, (2021) 


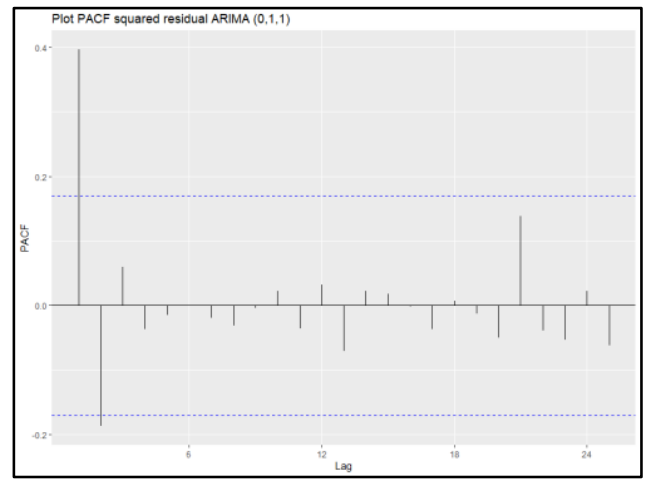

Gambar 7. Plot PACF Residual Kuadrat Model $\operatorname{ARIMA}(0,1,1)$

Pada gambar diatas terlihat bahwa plot ACF cut off pada lag pertama. Namun, untuk plot PACF terlihat cut off after lag ke-2. Sehingga, dapat dibentuk dua model $\operatorname{ARCH}(p)$ dan dua model $\operatorname{GARCH}(p, q)$. Beberapa alternatif model dugaan ARCH dan GARCH yang dapat digunakan :
1. Model 1 : ARCH(1)

2. Model 2 : ARCH(2)

3. Model 3 : GARCH $(1,1)$

4. Model 4 : $\operatorname{GARCH}(1,2)$

\section{Penaksiran beserta Uji Signifikansi Parameter ARCH-GARCH}

Sesudah didapatkan model dugaan ARCH dan GARCH, maka tahap berikutnya yaitu penaksiran parameter untuk setiap model. Hasil penaksiran parameter tersebut akan diuji signifikansinya untuk melihat apakah parameter yang ditaksir memiliki keberartian atau layak masuk ke dalam suatu model. Hasil penaksiran parameter bersama uji kesignifikansian parameter dapat dilihat dalam tabel berikut ini.

Tabel 3. Hasil penaksiran parameter beserta uji signifikansi parameter model ARCH-GARCH

\begin{tabular}{|c|c|c|c|c|c|c|}
\hline \multirow{2}{*}{ Model } & Parameter & Estimasi & $\begin{array}{c}\text { Standar } \\
\text { Error }\end{array}$ & t-hitung & $p$-value & Keterangan \\
\hline \multirow{3}{*}{ ARCH(1) } & $\alpha_{0}$ & 155.15429 & 11.48753 & 13.506 & $<2 \mathrm{e}-16$ & Signifikan \\
\cline { 2 - 7 } & $\alpha_{1}$ & 0.21975 & 0.09237 & 2.379 & 0.0174 & Signifikan \\
\hline \multirow{3}{*}{ ARCH(2) } & $\alpha_{0}$ & 95.1986 & 15.1059 & 6.302 & $2.94 \mathrm{e}-10$ & Signifikan \\
\cline { 2 - 7 } & $\alpha_{1}$ & 0.4237 & 0.1182 & 3.584 & 0.000338 & Signifikan \\
\cline { 2 - 7 } & $\alpha_{2}$ & 0.4750 & 0.1183 & 4.016 & $5.92 \mathrm{e}-05$ & Signifikan \\
\hline \multirow{3}{*}{ GARCH(1,1) } & $\alpha_{0}$ & $1.905 \mathrm{e}+02$ & $1.049 \mathrm{e}+02$ & 1.816 & 0.0694 & Tidak Signifikan \\
\cline { 2 - 7 } & $\alpha_{1}$ & $1.624 \mathrm{e}-01$ & $7.802 \mathrm{e}-02$ & 2.082 & 0.0373 & Signifikan \\
\cline { 2 - 7 } & $\beta_{1}$ & $3.426 \mathrm{e}-12$ & $4.719 \mathrm{e}-01$ & 0 & 1 & Tidak Signifikan \\
\hline \multirow{3}{*}{ GARCH(1,2) } & $\alpha_{0}$ & $1.799 \mathrm{e}+02$ & $3.848 \mathrm{e}+02$ & 0.468 & 0.640 & Tidak Signifikan \\
\cline { 2 - 7 } & $\alpha_{1}$ & $1.672 \mathrm{e}-01$ & $8.097 \mathrm{e}-02$ & 2.064 & 0.039 & Signifikan \\
\cline { 2 - 7 } & $\alpha_{2}$ & $4.843 \mathrm{e}-02$ & $3.807 \mathrm{e}-01$ & 0.127 & 0.899 & Tidak Signifikan \\
\cline { 2 - 7 } & $\beta_{1}$ & $5.435 \mathrm{e}-12$ & 2.119 & 0 & 1 & Tidak Signifikan \\
\hline
\end{tabular}

Dari hasil di atas terlihat bahwa model ARCH(1) memiliki parameter $\alpha_{0}$ dan $\alpha_{1}$ yang memiliki keberartian dalam model. Begitu pula dengan model $\operatorname{ARCH}(2)$ memiliki parameter $\alpha_{0}, \alpha_{1}$, dan $\alpha_{2}$ yang memiliki keberartian juga dalam model. Model GARCH $(1,1)$ memiliki parameter $\alpha_{1}$ yang berarti dalam model, tetapi tidak dengan parameter $\alpha_{0}$ dan $\beta_{1}$. Model $\operatorname{GARCH}(1,2)$ memiliki parameter $\alpha_{1}$ yang berarti dalam model, tetapi tidak dengan parameter $\alpha_{0}, \alpha_{2}$, dan $\beta_{1}$.

\section{Pemilihan Model ARCH-GARCH Terbaik}

Berdasarkan model dugaan ARCH dan GARCH yang telah dibentuk sebelumnya, selanjutnya akan dipilih model dugaan terbaik yang akan digunakan untuk menduga indeks harga saham PT Verena
Multi Finance Tbk. Untuk memilih model dugaan ARCH-GARCH terbaik, dapat dilihat dari model dengan nilai AIC terkecil. Untuk menentukan orde ARCH/GARCH yang akan digunakan, akan dihitung AIC dengan rumus sebagai berikut :

$$
\begin{gathered}
A I C_{c}=-2 \log \text { likelihood }+2(q+ \\
\text { 1) }\left(\frac{N}{N-q-2}\right),
\end{gathered}
$$

tidak konstan.

$$
\begin{gathered}
A I C_{c}=-2 \log \text { likelihood }+2(q+ \\
\text { 2) }\left(\frac{N}{N-q-3}\right),
\end{gathered}
$$

konstan.

Dengan :

$\mathrm{N}=$ Ukuran Data

$q=$ Orde Autoregressive

Fajriyah Fitriyani ${ }^{1}$, Salsabila Fasya $\mathrm{A}^{2}$, Muhammad Irfan $\mathrm{R}^{3}$, Teguh Ammar T ${ }^{4}$

J Statistika Vol. 14, No. 1, (2021) 
Tabel 4. Nilai AIC Masing-Masing Model ARCH-GARCH Indeks Harga Saham PT Verena Multi Finance Tbk

\begin{tabular}{|c|c|c|c|c|c|}
\hline Model & N & $Q$ & Log Likelihood & $\begin{array}{c}\text { AICc Tidak } \\
\text { Konstan }\end{array}$ & AICc Konstan \\
\hline ARCH(1) & 132 & 1 & -526.0697 & 1056.233 & 1058.327 \\
\hline ARCH(2) & 132 & 2 & -519.5263 & 1045.24 & 1047.368 \\
\hline
\end{tabular}

Dari Tabel 4. terlihat AIC baik konstan maupun non konstan semakin menurun, dan pada model $\operatorname{ARCH}(2)$ memiliki AIC terkecil, sehingga model ARCH-GARCH yang akan dipakai untuk menduga indeks harga saham PT Verena Multi Finance Tbk adalah $\mathrm{ARCH}(2)$.

Untuk mendapatkan persamaan dari model $\operatorname{ARCH}(2)$, substitusikan taksiran parameter pada Tabel 3. ke dalam persamaan berikut.

$$
\begin{gathered}
\sigma_{t}^{2}=\alpha_{0}+\alpha_{1} \varepsilon_{t-1}^{2}+\alpha_{2} \varepsilon_{t-2}^{2}+\cdots \\
+\alpha_{p} \varepsilon_{t-p}^{2}
\end{gathered}
$$

Sehingga, akan diperoleh persamaan sebagai berikut.

$\sigma_{t}^{2}=95.1986+0.4237 \varepsilon_{t-1}^{2}+0.475 \varepsilon_{t-2}^{2}$

Persamaan tersebut memiliki arti bahwa variansi indeks harga saham PT Verena Multi Finance Tbk pada periode $\mathrm{t}$ ditemukan oleh suatu konstanta (95.1986), sisaan kuadrat pada satu periode sebelumnya dengan proporsi sebesar $42.37 \%$, dan sisaan kuadrat pada dua periode sebelumnya dengan proporsi sebesar $47.5 \%$.

\section{Peramalan Indeks Harga Saham PT Verena Multi Finance Tbk}

Setelah memilih model ARCH-GARCH terbaik, maka akan diperoleh model gabungan $\operatorname{ARIMA}(0,1,1)-\operatorname{ARCH}(2)$ untuk memprediksi indeks harga saham PT Verena Multi Finance Tbk sebagai berikut.

$$
\begin{aligned}
X_{t}=-0.3120 X_{t-1} & +\varepsilon_{t}+95.1986 \\
& +0.4237 \varepsilon_{t-1}^{2} \\
& +0.475 \varepsilon_{t-2}^{2}
\end{aligned}
$$

Berikutnya akan dilakukan peramalan (forecasting) menggunakan model $\operatorname{ARIMA}(0,1,1)$ dan varians residual $\mathrm{ARCH}(2)$. Hasil peramalan indeks harga saham PT Verena Multi Finance Tbk untuk dua tahun kedepan diperlihatkan pada tabel di bawah ini.

Tabel 5. Hasil peramalan indeks harga saham PT Verena Multi Finance Tbk

\begin{tabular}{|c|c|c|}
\hline Periode & Forecast & Sigma \\
\hline 1 Januari 2020 & 112.2 & 17.31 \\
\hline 1 Februari 2020 & 102.4 & 16.77 \\
\hline
\end{tabular}

\begin{tabular}{|c|c|c|}
\hline 1 Maret 2020 & 102.4 & 17.82 \\
\hline 1 April 2020 & 102.4 & 17.97 \\
\hline 1 Mei 2020 & 102.4 & 18.46 \\
\hline 1 Juni 2020 & 102.4 & 18.71 \\
\hline 1 Juli 2020 & 102.4 & 19.01 \\
\hline 1 Agustus 2020 & 102.4 & 19.22 \\
\hline $\begin{array}{c}\text { 1 September } \\
\text { 2020 }\end{array}$ & 102.4 & 19.42 \\
\hline 1 Oktober 2020 & 102.4 & 19.59 \\
\hline $\begin{array}{c}\text { 1 November } \\
\text { 2020 }\end{array}$ & 102.4 & 19.74 \\
\hline $\begin{array}{c}\text { 1 Desember } \\
\text { 2020 }\end{array}$ & 102.4 & 19.87 \\
\hline 1 Januari 2021 & 102.4 & 19.98 \\
\hline 1 Februari 2021 & 102.4 & 20.08 \\
\hline 1 Maret 2021 & 102.4 & 20.16 \\
\hline 1 April 2021 & 102.4 & 20.23 \\
\hline 1 Mei 2021 & 102.4 & 20.30 \\
\hline 1 Juni 2021 & 102.4 & 20.35 \\
\hline 1 Juli 2021 & 102.4 & 20.40 \\
\hline 1 Agustus 2021 & 102.4 & 20.44 \\
\hline $\begin{array}{c}\text { 1 September } \\
\text { 2021 }\end{array}$ & 102.4 & 20.48 \\
\hline 1 Oktober 2021 & 102.4 & 20.51 \\
\hline $\begin{array}{c}\text { 1 November } \\
\text { 2021 }\end{array}$ & 102.4 & 20.54 \\
\hline $\begin{array}{c}\text { 1 Desember } \\
\text { 2021 }\end{array}$ & 102.4 & 20.56 \\
\hline
\end{tabular}

Langkah berikutnya akan dilaksanakan evaluasi ketepatan model pendugaan antara persamaan model ARIMA(0,1,1)-ARCH(2) yang telah dibentuk dengan data indeks harga saham PT Verena Multi Finance Tbk. Evaluasi tersebut menggunakan MAD (Mean Absolute Deviation) sebagai ukurannya. Hasil prediksi tidak terpaut jauh jika dibandingkan oleh data asli, artinya model yang terbentuk sudah cukup baik untuk memprediksi indeks harga saham PT Verena Multi Finance Tbk. Nilai MAD hasil peramalan indeks harga saham PT Verena Multi Finance Tbk sebesar 28.01674. Hasil perhitungan MAD membuktikan bahwa model yang didapat sudah lumayan baik digunakan dalam memprediksi. Selain itu, evaluasi juga dilaksanakan dengan menghitung nilai MAPE (Mean Absolute Percentage Error). Nilai MAPE

Fajriyah Fitriyani ${ }^{1}$, Salsabila Fasya $\mathrm{A}^{2}$, Muhammad Irfan $\mathrm{R}^{3}$, Teguh Ammar T ${ }^{4}$

J Statistika Vol. 14, No. 1, (2021) 
hasil peramalan indeks harga saham PT Verena Multi Finance Tbk sebesar 22.9971\%.

Menurut Lewis (1982), nilai MAPE dapat digolongkan ke dalam 4 kriteria yaitu jika MAPE bernilai kurang dari $10 \%$ maka hasil prediksi digolongkan ke dalam sangat akurat. Untuk MAPE bernilai antara $10 \%$ dan $20 \%$ maka hasil prediksi dikatakan baik. Nilai MAPE sebesar 20\% hingga $50 \%$ dikategorikan wajar, dan untuk nilai MAPE lebih besar dari 50\% maka digolongkan ke dalam tidak akurat.

Maka dari penggolongan tersebut terlihat bahwa nilai MAPE berbanding lurus dengan kesalahan hasil prediksi. Berdasarkan Lewis (1982), maka hasil peramalan indeks harga saham PT Verena Multi Finance Tbk memiliki kemampuan pendugaan yang wajar.

\section{KESIMPULAN}

Jika dilihat dari hasil analisis pada bagian hasil dan pembahasan, dapat diambil beberapa kesimpulan, yaitu :

1. Pada kasus data indeks harga saham PT Verena Multi Finance Tbk menunjukkan ketidakstabilan variansi residual yaitu terdapat efek heteroskedastisitas. Model ARIMA terbaik yaitu $\operatorname{ARIMA}(0,1,1)$ tidak dapat digunakan dalam mengatasi data yang mengandung efek heteroskedastisitas, maka digunakanlah model GARCH. Model GARCH terbaik yang diperoleh untuk melakukan peramalan indeks harga saham PT Verena Multi Finance Tbk adalah model ARCH(2). Maka, didapatkan persamaan model $\operatorname{ARIMA}(0,1,1)-\mathrm{ARCH}(2)$ seperti dibawah ini.

$X_{t}=-0.3120 X_{t-1}+\varepsilon_{t}+95.1986+0.4237 \varepsilon_{t-1}^{2}$

$$
+0.475 \varepsilon_{t-2}^{2}
$$

2. Model ARIMA(0,1,1)-ARCH(2) mampu memprediksi secara baik data indeks harga saham PT Verena Multi Finance Tbk, hal ini dapat dilihat dari akurasi peramalan memakai MAD (Mean Absolute Deviation) dan MAPE (Mean Absolute Percentage Error). Didapatkan nilai MAD sebesar 28.01674 dan nilai MAPE sebesar 22.9971\%. Dari nilai MAD dan MAPE tersebut terlihat jika model yang didapat sudah lumayan baik dalam memprediksi.

\section{DAFTAR PUSTAKA}

Arch, M., Garch, D. A. N., Peramalan, P., Price, S., Corp, D., Bilondatu, R. N., \& Isa, D. R. (2019). HARGA SAHAM PT. COWELL DEVELOPMENT Tbk. 13, 9-18.

Ari Pani Desvina, N. R. (2016). Penerapan Metode ARCH / GARCH dalam Peramalan Indeks
Harga Saham Sektoral. Jurnal Sains Matematika Dan Statistika, 2(I), 1-10.

Bollerslev, T. (1986). Generalized Auto Regressive Heteroscedastic Model, Journal of Econometric, 31 : 307 - 327.

Faustina, R. S., Agoestanto, A., \& Hendikawati, P. (2017). Model Hybrid ARIMA-GARCH untuk Estimasi Volatilitas Harga Emas. UNNES Jurnal of Mathematics, 6(1), 11-24.

Garch-m, H. I. N. M. (2014). Peramalan volatilitas menggunakan model. 3, 655-662.

Gaussian, J. (2016). 11 , 2 , 3. 5, 705-715.

Irawan, W. (2019). Peramalan Harga Saham PT. Unilever Tbk dengan Menggunakan Metode ARIMA. Jurnal Matematika UNAND, 4(3), 80. $\quad$ https://doi.org/10.25077/jmu.4.3.8089.2015

Islam, U., Sunan, N., Yogyakarta, K., Islam, U., \& Sunan, N. (n.d.). GABUNGAN REGIONAL ASIA TERHADAP INDEKS HARGA SAHAM GABUNGAN INDONESIA Widodo. 4988, 148-164.

Juanda, Bambang, \& Junaidi. (2012). Ekonometrika Deret Waktu Teori dan Aplikasi, Bogor: IPB Press.

Listya, D., \& Sutijo, B. (2013). Metode Peramalan Indeks Harga Saham Gabungan (IHSG) Nikkei 255 dengan Pendekatan Fungsi Transfer. Jurnal Sains Dan Seni Pomits, 2(2), D-271-D-274.

Matematika, J., Matematika, F., Ilmu, D. A. N., \& Alam, P. (2018). Analisis peramalan indeks harga konsumen menggunakan metode arch garch berbantuan software eviews.

Metode, M., \& Dengan, G. (2016). Analisis Volatility Forecasting Sembilan Bahan Pokok Menggunakan Metode Garch Dengan Program R. Unnes Journal of Mathematics, 5(1), 90-99. https://doi.org/10.15294/ujm.v5i1.13109

Puspatika, K., \& Kusumawati, Y. (2018). Peramalan Harga Cabai Dengan Metode Arima Arch- Garch Dan Single Moving Average Di Kota Semarang. Journal JOINS Udinus, 03(02), 192-201.

Saida, M. D. N., Sudarno, \& Hoyyi, A. (2016). Pemodelan Return Indeks Harga Saham Gabungan Menggunakan Threshold Generalized Autoregressive Conditional Heteroscedasticity (Tgarch). Jurnal Gaussian, 5(3), 465-474.

Sari, F. T., Mariani, S., Matematika, J., \& Semarang, U. N. (2016). Perbandingan Taksiran Value at Risk Dengan Program R

Fajriyah Fitriyani ${ }^{1}$, Salsabila Fasya $\mathrm{A}^{2}$, Muhammad Irfan $\mathrm{R}^{3}$, Teguh Ammar T ${ }^{4}$

J Statistika Vol. 14, No. 1, (2021) 
J Statistika Vol. 14, No. 1, (2021), Hal. 11-23

Dan Matlab Analisis Investasi Saham Menggunakan Metode Garch. Unnes Journal of Mathematics, 5(2), 118-126. https://doi.org/10.15294/ujm.v5i2.13120

Sidiq, A., Indeks, P., Sti, S., \& Pergerakan, H. T. (2010). INDEKS SAHAM GABUNGAN PADA BEI Ahmad Sidiq. 1(November), 1-18.

Syukrina, Filzah. (2020). Penerapan Metode Peramalan Model GARCH Dalam Memprediksi Indeks Dst. Skripsi. Tidak diterbitkan. Jatinangor: Fakultas Matematika dan Ilmu Pengetahuan Alam, Universitas Padjadjaran.

Tita Deitiana1; Stella. (2009). Harga Saham Gabungan Bursa Efek Indonesia. 10(1), 2230.

Zach. (2020). How to Calculate Mean Absolute Percentage Error (MAPE) in Excel. https://www.statology.org/mape-excel/ (diakses tanggal 15 Mei 2021)

Fajriyah Fitriyani ${ }^{1}$, Salsabila Fasya $\mathrm{A}^{2}$, Muhammad Irfan $\mathrm{R}^{3}$, Teguh Ammar $\mathrm{T}^{4}$ / 